\title{
DEVELOPMENT AND OPTIMIZATION OF AN ULTRA WIDEBAND MINIATURE MEDICAL ANTENNA FOR RADIOMETRIC MULTI-CHANNEL MULTI-FREQUENCY THERMAL MONITORING
}

\author{
Mikhail Sedankin \\ State Research Center - Burnasyan Federal Medical Biophysical Center of Federal ${ }^{1}$ \\ Fundamentals of Radio Engineering Department, National Research University \\ «Moscow Power Engineering Institute» \\ 14 Krasnokazarmennaya str., Moscow, Russian Federation, 111250 \\ Department of Biocybernetic Systems and Technologies \\ Federal state budgetary educational institution of higher education \\ "MIREA - Russian Technological University» \\ 78 Vernadskogo ave., Moscow, Russia, 119454 \\ msedankin@yandex.ru \\ Vitaly Leushin ${ }^{2}$ \\ Hyperion Ltd \\ 34 Kutuzovski ave., Moscow, Russia, 121170 \\ ra3bu@yandex.ru \\ Alexander Gudkov ${ }^{2}$ \\ profgudkov@gmail.com \\ Igor Sidorov ${ }^{2}$ \\ igor_sidorov@mail.ru \\ Sergey Chizhikov ${ }^{2}$ \\ chigikov95@mail.ru \\ Lev Mershin \\ State Research Center - Burnasyan Federal Medical Biophysical Center of Federal ${ }^{1}$ \\ mershinl@mail.ru

$$
\begin{gathered}
\text { Sergey Vesnin }^{2} \\
\text { vesnin47@gmail.com }
\end{gathered}
$$ \\ ${ }^{1}$ Medical Biological Agency \\ 23 Marshala Novikova str., Moscow, Russia, 123098 \\ ${ }^{2}$ Federal state budgetary educational institution of higher education \\ «Bauman Moscow state technical University» (National Research University) \\ 5 2nd Baumanskaya str., p. 1, Moscow, Russia, 105005
}

\footnotetext{
Abstract

The article is devoted to the development of a printed ultra-wideband miniature antenna that can be used for microwave radiometry. An antenna design with a ring-shaped radiator has been proposed, which provides reception of microwave radiation from biological tissues in the $1800-4600 \mathrm{MHz}$ range. The results of mathematical modeling of the antenna electromagnetic field in biological tissues using the finite difference time domain (FDTD) method are presented. Optimization of the antenna design has been carried out to ensure acceptable matching parameters and optimal antenna functionality. The developed antenna has a height of $6 \mathrm{~mm}$ and a calculated mass of $5 \mathrm{~g}$; it is planned to manufacture a dielectric substrate based on PDMS polymer with the addition of barium titanate. The issues of calculating the antenna parameters (measurement depth, resolution and distribution of radiation power over the volume of biological tissue, sensitivity, etc.) are considered. The research results and design parameters
} 
of the developed antenna demonstrated the effectiveness of the new antenna and the possibility of its adaptation to the object of research. Considering the presence of an ultra-wide band and miniature dimensions, the antenna can be a sensor of a multi-frequency multi-channel microwave radiothermograph.

Keywords: microwave radiometry, FDTD method, temperature monitoring, multi-channel radiometer, multi-frequency radiometer.

DOI: $10.21303 / 2461-4262.2020 .001517$

\section{Introduction}

In recent years, the interest of specialists in the use of microwave radiometry (MR) in medicine has been growing. Unlike IR thermography, which visualizes the temperature of the skin, MR allows to measure the temperature of deeper tissues $(\approx 5-7 \mathrm{~cm})$. MR is used in the healthcare system of Russia and is implemented in a medical technology called «RTM-diagnostics» [1]. The main area of application of the technology is diagnostics and monitoring of the effectiveness of the treatment of breast diseases [2, 3]. The direction of using MR for predicting the risk of stroke development based on measuring the temperature of the carotid arteries is actively developing [4, 5], as well as diagnostics and monitoring of diseases and the functional state of the brain [6, 7]. Monitoring of brain temperature using MR as a control of therapy for stroke and traumatic brain injury is presented in [8]. There are other applications of MR in medicine, which can be found in the works [9-11]. Currently, patients are examined using a single-channel medical microwave radiometer «RTM-01-RES» [1]. This device consists of a dual-band sensor and an information processing unit. The dual-band sensor detects microwave and infrared radiation from biological tissues. The temperature is measured at several points of the examined organ. The measurement time at one point is 5-7 seconds, so the total examination time takes 2.5-3 minutes. After completion of measurements, the software visualizes the results in the form of thermograms and thermal fields of internal tissues and skin in 2D mode. In other words, the brightness (average) temperature is visualized, but a thermodynamic temperature is required, which changes with depth in the human body. Obviously, to improve the efficiency of diagnostics, it is necessary to develop multi-channel multi-frequency devices that allow monitoring the temperature of biological tissues simultaneously at several points and in different frequency ranges [12], i. e. allow to work in 3D mode. To solve this problem, it is necessary to find optimal conditions under which it is possible to operate a medical device in a multi-channel and multi-frequency mode simultaneously, provided that the manufacturability and low cost of the medical device are ensured. Defining importance in this context is the creation of an ultra-wideband miniature antenna. First of all, such an antenna should have the minimum dimensions to implement as many measurement channels as possible in the area under investigation of biological object, which will ensure the optimal resolution of multiple antennas combined into an antenna system. At the same time, a ultra-wide wide working band of the antenna will make it possible to work in several frequency ranges, and therefore will allow visualizing the internal temperature from different depths of biological tissues. In addition, the design of the antenna should provide the ability to mounting various temperature sensors for additional measuring for example in the infrared range. Several such antennas can be integrated into a single conformal antenna system and receive a microwave signal from each antenna using several miniature radiometers of various frequency ranges attached to the patient's body. Radiometers with a microwave broadband microwave switch will sequentially receive a signal from each antenna and visualize the thermal field of biological tissues in real time in several microwave ranges. Thermal monitoring will allow to fully control changes in the temperature of organs and biological tissues and detect the slightest changes in their state based on the recording and analysis of the dynamics of temperature data. Thus, an actual problem is to develop a small-sized ultra-wideband antenna, which can be used as part of a multi-channel multi-frequency microwave radiometer, which provides $3 \mathrm{D}$ visualization of the distribution of internal thermodynamic temperatures of biological tissues.

\section{Literature review and problem statement}

The creation of miniature microwave radiometers combined with miniature antennas operating in a multi-frequency mode opens up the possibility of constructing multi-channel multi-frequency microwave radiometers. Today, various types of miniature ceramic antennas are widely 
known, which have proven themselves in telecommunications equipment using Wi-Fi, Bluetooth, etc. But such ceramic antennas receive a signal from free space, while MR antennas must receive a signal from human biological tissues, i. e. environments with high electrical losses. Thus, the developed antenna must be matched to human tissues, which have an order of magnitude higher dielectric constant. To receive the own radiation of human tissues, special antennas are used, coordinated with the human body. Papers $[13,14]$ provide an overview of existing multi-channel and multi-frequency radiometers and medical antennas designed to measure the temperature of internal tissues of the human body. Today, the following types of antennas are widely used in the existing radiometers: waveguide antennas [14, 15], printed antennas [6, 11, 16-19], as well as intracavitary antennas [20]. It is obvious that the waveguide antennas used today in the healthcare system $[1,14,15]$ are not broadband and are difficult to use in a multi-channel device. These antennas are large in size, so it is difficult to ensure their reliable attachment to the human body. It is possible to combine two waveguide antennas of different sizes in one antenna, providing different measurement depths due to the size of the aperture [15], but this will make it possible to work only in two-channel mode at one point. In addition, such a structure will also have significant dimensions.

The work [16] presents the results of research related to the creation of a single-frequency multi-channel radiometer for monitoring the temperature of the brain. The device includes a singlechannel miniature radiometer, 8 printed slot antennas (Rogers 3010 material) and a complex 8-channel microwave switch, which in series connect one of the antennas to the input of the radiometer. This device is rather miniature, but its antennas do not allow measuring the internal temperature in a multi-frequency mode, they are not broadband. It should be noted that in general, the doctor does not know at what depth the heat source is located. The microwave radiometer should be able to detect thermal anomalies located both in depth and on the surface of the body. Therefore, when examining a patient using microwave radiometry to detect thermal anomalies located at different depths, it is necessary for the antenna to work in several frequency ranges.

For multi-channel multi-frequency measurements, taking into account the miniaturization requirements, printed antennas are more suitable, having small dimensions and low weight. The substrate thickness for printed antennas is usually less than $2 \mathrm{~mm}$. Printed antennas have less effect on skin temperature. Several printed antennas are currently known that meet these requirements and can be used for multi-channel and multi-frequency systems. The following classes of printed antennas can be distinguished: spiral antennas [6], elliptical antennas [21, 22], patch antennas [23], slot antennas [24, 25] and dipole or dipole printed antennas [26]. In [15], printed antennas are presented, the radiator of which has a «butterfly» shape. However, such antennas are not broadband and can’t be used in multi-frequency mode; it is also difficult to ensure optimal fit of these antennas, given that ceramic dielectric materials are not flexible, to the surface of a biological object of complex shape.

In [17], two multi-frequency antennas $\left(\right.$ size $30 \times 30 \mathrm{~mm}^{2}$ ) are presented for research related to the development of a portable wireless microwave radiometer. The first implementation is a dual-frequency antenna consisting of two antennas designed for different frequency bands of $0.406 \mathrm{GHz}$ and 1.4 GHz on a single substrate (Rogers 3010 material). This antenna is designed to examine the heart by contact with the chest surface. Moreover, in each range, the antenna is quite narrow-band. In addition, the implementation of the radiator in the form of a rectangular spiral does not allow placing additional thermal sensors in the center of the antenna aperture. The second implementation of the multi-frequency antenna (Rogers RO4350B material) is a three-frequency antenna $(1.4 \mathrm{GHz}, 2.7 \mathrm{GHz}$ and $4.9 \mathrm{GHz}$ ) for measuring temperature when installed on the surface of the abdominal wall. The radiators of both antennas are slightly spaced apart, and a separate power line is connected to each radiator. It is difficult to use such technical solutions in a multi-channel multi-frequency radiometer, or a serious revision of the design is required. The works [18, 27-29] present the results of studies on the creation of broadband antennas that ensure the reception of the own radiation of biological tissues in several frequency ranges. Today this is the most demanded line of research. The most wellknown ultra-wideband antenna is an antenna based on a spiral radiator. The work [18] describes the development of a broadband antenna. The key element of the sensor is $\varnothing 25 \mathrm{~mm}$ conical log-spiral antenna (material Rogers3010) integrated into an low-cost $\varnothing 28 \mathrm{~mm}$ radiometric sensor. The antenna design has been optimized for deep brain temperature measurement only in the 1.1-1.6 GHz band. 
As a result of research, the antenna provides a theoretical bandwidth of $\Delta f=500 \mathrm{MHz}$, which is comparable to waveguide antennas used in medicine $[1,14,15]$. It is problematic to use this antenna for use in a multi-channel multi-frequency radiometer, or a serious revision of the design is needed. In addition, Rogers materials are certainly more flexible than dielectric ceramics, but not enough. The work [27] presents the development of an epidermal ultra-wideband antenna based on an asymmetric slot in the form of the Jerusalem cross. The antenna is based on Rogers 3003 material with $\varnothing 25 \mathrm{~mm}$. By the type of radiator, this antenna can be classified as dipole or dipole printed antennas. The prototype was tested on four different volunteers, corresponding to body regions such as the carotid artery, instep, and sole of the foot. In all cases, the antenna was matched, showing broadband between 1.8 and $5 \mathrm{GHz}$. In addition, the antenna has very low return radiation up to $4 \mathrm{GHz}$, which reduces interference and minimizes its effect on brightness temperature. The developed antenna is easy to manufacture and comfortable for patients. It has a simple and flexible design so it can be used on other areas of the body and can be easily integrated into wearable microwave sensors, but no additional sensors can be installed in the center of the aperture.

In article [28], the results of a study of a planar single-threaded spiral antenna designed to measure the intrinsic electromagnetic radiation of the brain in the frequency range $3-5 \mathrm{GHz}$ are presented. The antenna is manufactured using Arlon AD1000 material. The center conductor of the coaxial connector and the flat printed coil are connected through in the laminate. The edge metallization of the boards and the top layer of the conductor form an integral metal shield in the form of a short-circuited cylinder. On the basis of the developed design of the sensor-applicator, the authors suggest a multi-position antenna system can be created to increase the volume of the investigated area and identify active areas of the brain. This antenna is made on the basis of a spiral radiator, therefore, all the features of spiral antennas belong to it.

In article [29] describes an ultra-wideband antenna created on the basis of an radiator in the form of a spiral Archimedes on the Rogers 4003C material. The dielectric substrate diameter exceeds $50 \mathrm{~mm}$. This antenna is made on the basis of a spiral radiator, therefore, all the features of spiral antennas belong to it, and it is impossible to mounting additional sensors in the center of the aperture. Although, according to the authors' data, the antenna has high efficiency and ultra-wide bandwidth (1-4 GHz), it is rather difficult to use it to build a multi-channel multi-frequency microwave radiometer.

Based on the analysis of information sources, we can conclude that a miniature ultra-wideband antenna is needed to build a multi-channel multifrequency radio thermograph, comparable in diagnostic properties to antennas already used in the healthcare system. This paper presents studies of an original small-sized ultra-wideband antenna with a diameter of no more than $22 \mathrm{~mm}$ based on a ring radiator, in the center of which additional temperature sensors can be placed.

\section{The aim and objectives of research}

The aim of research is to develop a broadband miniature printed antenna designed to register the own electromagnetic radiation of biological tissues, based on mathematical calculation of its main parameters with subsequent design optimization.

To achieve this aim, it is necessary to solve the following objectives:

- to carry out mathematical modeling of the electric field of the printed ring antenna with optimization of geometric parameters;

- to calculate and analyze the parameters and properties of the antenna (resolution, sensitivity, etc.) to select the optimal design.

\section{Development of a miniature ultra-wideband printed antenna for a medical microwave radiometer}

To create an ultra-wideband miniature printed antenna, it is necessary to numerically simulate the antenna's electromagnetic field in tissues. The brightness temperature $\operatorname{Tbr}(r)$ measured by a medical radiometer is related to the physical temperature $T(r)$ of biological tissues as follows:

$$
T_{b r}=\int_{-\infty}^{\infty} T(r) \cdot W(r) \mathrm{d} V,
$$


where $W(r)$ - the weight radiometric function, $V$ - the volume of the biological object over which the integration is carried out.

$$
W(r)=\frac{\frac{\sigma(r)}{2}|\overrightarrow{E(r)}|^{2}}{\int_{-\infty}^{\infty} \frac{\sigma(r)}{2}|\overrightarrow{E(r)}|^{2} \mathrm{~d} V},
$$

where $E(r)$ - the electric field strength, $\sigma(r)$ - the electrical conductivity of the biological object.

To calculate the electric field, let's use the numerical methods used in the electrodynamic simulation program. The calculations were carried out using the HIPERCONE FDTD program based on the EMTL interface (library of electromagnetic templates) [30, 31]. To calculate the electric field of the printed antenna, let's use the MF model in the form of a layered structure. The calculated mass of the antenna is $\approx 5 \mathrm{~g}$. The model of a biological object with an antenna (Fig. 1) consisted of several layers: skin, breast tissue, malignant tumor and muscles. The electrophysical parameters of the skin and muscles in the $1-8 \mathrm{GHz}$ range were determined according to [32,33], and of the mammary gland tissues and malignant tumors of the mammary glands according to the Debye model of the first order [34]. These parameters are shown in Fig. 2. The dimensions of the model were $100 \mathrm{~mm} \times 100 \times 100 \mathrm{~mm}$. The antenna axis is located in the center of the investigated volume at $X_{0}=50 \mathrm{~mm}, Y_{0}=50 \mathrm{~mm}$. Antenna design and radiator topology are shown in Fig. 3. The upper open portion of the backing contacts the body. In the course of mathematical modeling, the antenna parameters were optimized. The geometric dimensions $(D 1, D 2, \operatorname{Din} 1, \operatorname{Din} 2, H, h, S)$ and the dielectric constant $\varepsilon$ of the substrate were varied. When optimizing, VSWR antennas and the calculated antenna parameters (measurement depth, dimensions and shape parameters of the measurement area, temperature rise on the tumor projection, resolution, etc.), described in detail in [14], were used as performance criteria.
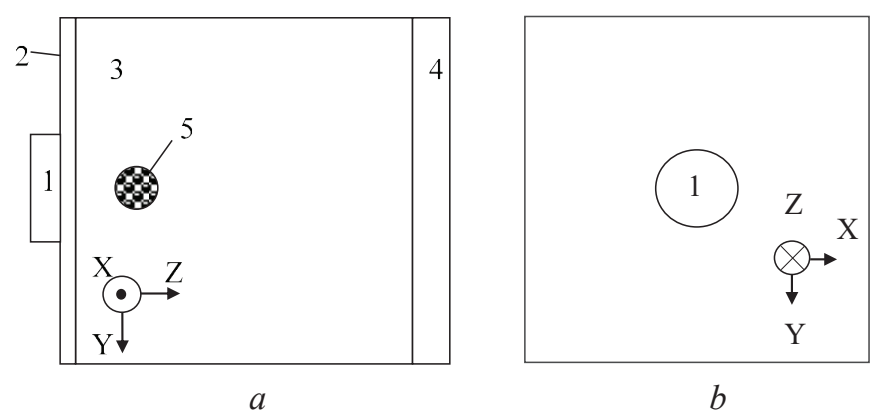

Fig. 1. Calculation model: $a$ - in the ZY plane, $b$ - in the XY plane;

1 - antenna, 2 - skin, 3 - breast layer, 4 - muscle, 5 - malignant tumor

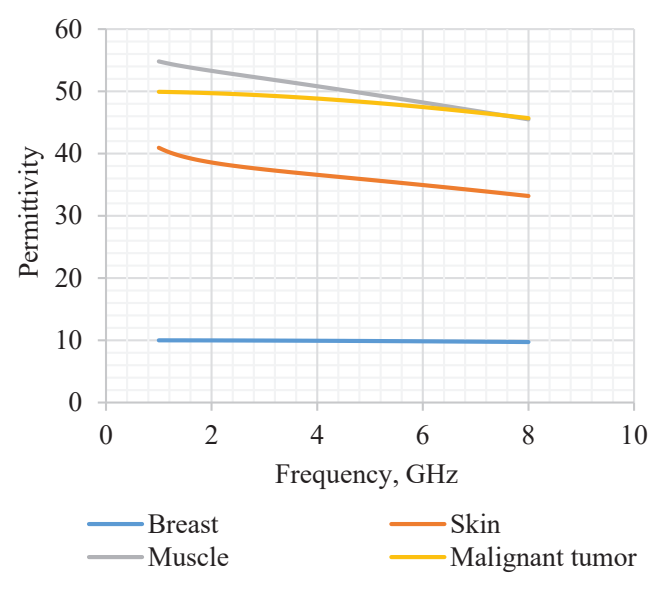

$a$

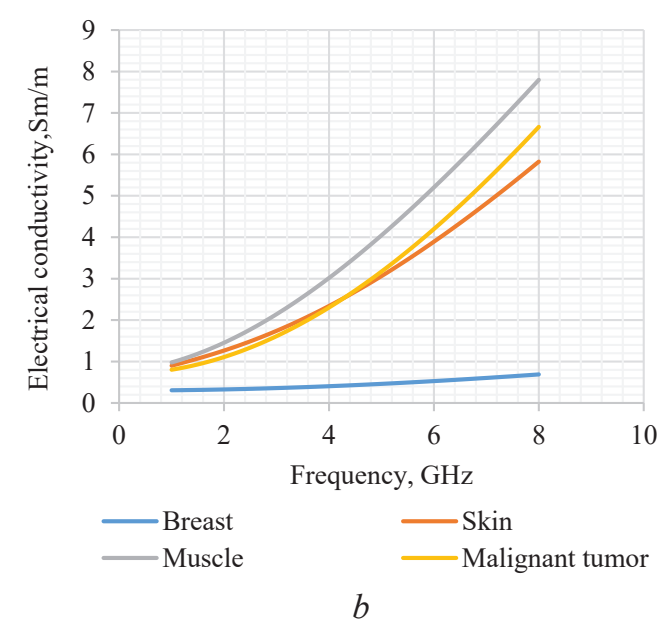

$b$

Fig. 2. Electrophysical parameters of biological tissues: $a$ - dielectric constant; $b$ - electrical conductivity 


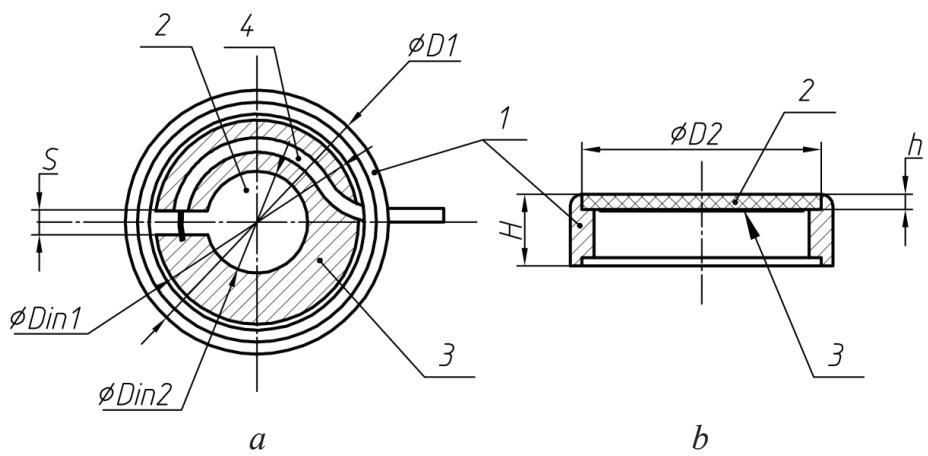

Fig. 3. Ring antenna design: $a$ - top view (cover not shown), $b$ - section (coaxial cable not shown); 1 - shielding case, 2 - dielectric substrate, 3 - radiator, 4 - coaxial cable

Fig. 4 shows the results of VSWR calculations for different dielectric permittivity $\varepsilon$ of the antenna substrate, corresponding to different available microwave materials. Optimization of the antenna parameters has been performed to obtain the best matching and to ensure the optimal calculated rational parameters presented below. As a result of numerical simulation, the optimal geometric parameters of the antenna were obtained: $D 1=22 \mathrm{~mm}, D 2=20 \mathrm{~mm}, h=1.28 \mathrm{~mm}, S=2 \mathrm{~mm}$, Din_1 $=17 \mathrm{~mm}, \operatorname{Din} 2=8.5 \mathrm{~mm}, H=10 \mathrm{~mm}$ and dielectric substrate permittivity $\varepsilon=27$.

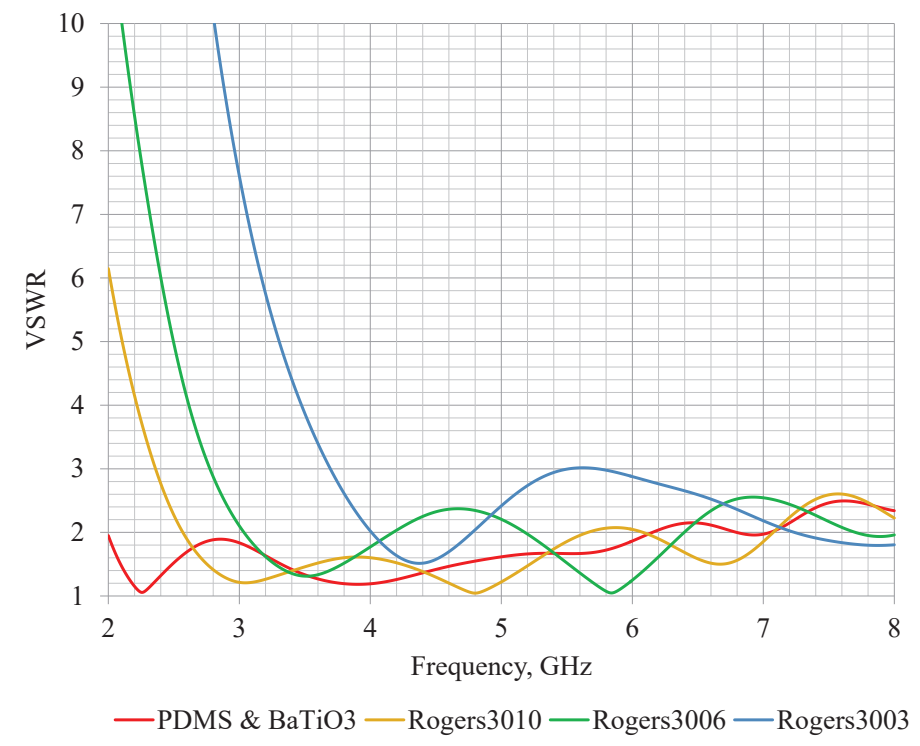

Fig. 4. VSWR of antenna at different dielectric constant $\varepsilon$ of the substrate

Fig. 5 shows the frequency dependences of the VSWR of the final version of the antenna and the antenna built on the basis of a round $\varnothing 22 \mathrm{~mm}$ waveguide with a «butterfly»-shaped radiator [14]. Obviously, the ring antenna has a much wider operating band compared to the $\varnothing 22 \mathrm{~mm}$ waveguide antenna. A distinctive feature of this antenna is a wider operating frequency band. As can be seen from the graph, the antenna has a VSWR of $\approx 1.5$ in the $1800-4600 \mathrm{MHz}$ band, i. e. the operating frequency band is $2800 \mathrm{MHz}$, which is significantly higher than the operating frequency band of antennas used in serial devices [1]. This makes it possible to use one antenna in several frequency ranges when used in multi-channel multi-frequency microwave radiometers with 3D visualization of the temperature distribution of internal tissues.

When describing the electric field of an antenna in the near field operating with a biological object, it is impossible to use traditional characteristics (directional pattern, gain, etc.). For medical antennas, a system of calculated rational parameters described in [14] has been developed. To interpret the antenna measurement depth, consider the area over which the internal temperature is measured. In this area, corresponding to a certain volume $V$ of a biological object, the full power 
of the antenna is dissipated during its operation in the transmission mode. The power dissipated in this volume, $V$, is determined as follows:

$$
L(V)=\frac{\int_{V} \frac{\sigma(r)}{2} \bar{E}(r)^{2} \mathrm{~d} V}{\int_{\infty} \frac{\sigma(r)}{2} \bar{E}(r)^{2} \mathrm{~d} V} .
$$

$L(V)$ tends to unity with increasing $V$. Inside the area of internal temperature measurement there is a power of $85 \%$, i. e. $L(V)=0.85$. For most antennas, this volume will be ellipsoidal. Let's designate the size of this volume along the $Z$-axis $-W_{z}$ and call it the depth of measurement of the internal temperature. The dimensions along the $X$ and $Y$ axes are denoted by $W_{x}$ and $W_{y}$, respectively. In Fig. 6 results of calculating the volume in which the temperature is measured in three frequency ranges for the new ring antenna.

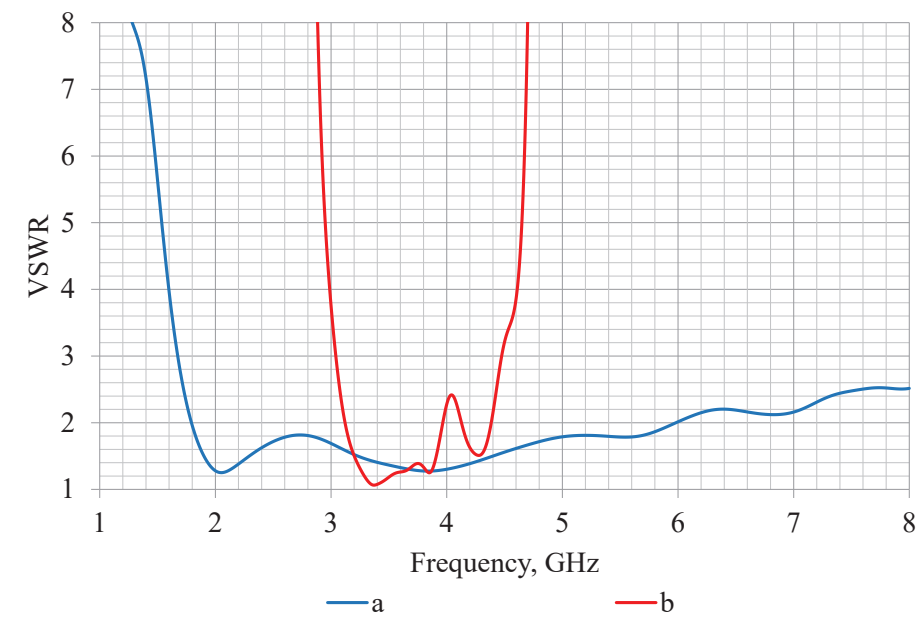

Fig. 5. Final VSWR for comparison:

$a$ - printed ring antenna $\varnothing 22 \mathrm{~mm}, b$ - waveguide antenna $\varnothing 22 \mathrm{~mm}$
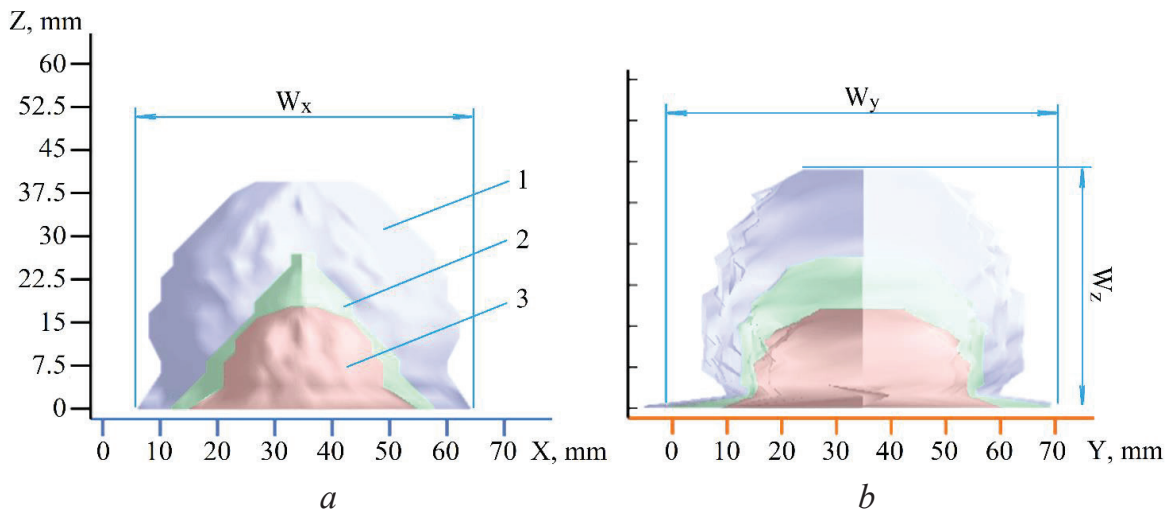

Fig. 6. Calculated range of volume under investigation (temperature measurement) at $85 \%$ level at three frequencies: $a$-in the $X Z$ plane, $b$ - in the $Y Z$ plane;

$$
1-2.3 \mathrm{GHz}, 2-3.3 \mathrm{GHz}, 3-4.3 \mathrm{GHz}
$$

In accordance with the methodology described in [14], the parameters of the printed antenna (Table 1) were calculated in three frequency ranges.

The $\Delta T_{b r}$ parameter is the increase in the brightness temperature on the projection of a malignant breast tumor with a diameter of $10 \mathrm{~mm}$, located at a depth of $10 \mathrm{~mm}$.

The developed antenna is distinguished by a significantly wider operating frequency band compared to traditional antennas $(2600 \mathrm{MHz}$ instead of $700 \mathrm{MHz})$; in this parameter, it is com- 
parable to the ultra-wideband spiral antenna described in [18]. As for the measurement depth, the proposed antenna is somewhat inferior to waveguide antennas $[14,15]$. This can be explained by the fact that the thickness of the dielectric, on which the topology of the radiator is printed, is much smaller than in a waveguide antenna, however, for many practical applications of a small-sized broadband antenna, this is not critical. In general, the antenna parameters are comparable to other antennas already used in medicine [14]. The use of this ultra-wideband antenna makes it possible to provide the condition for the optimal combination of multi-frequency and multi-channel in one construct of the prototype of the radiothermograph. Antenna design uses a flexible dielectric, which allows or opens the door to provide an optimal fit to the body. The set of antennas will be built into a flexible textile base made of shielding material (Radioscreen), which means that this antenna system has the potential to be optimally adaptable to a complex-shaped research object.

Table 1

Comparison of the parameters of the developed antenna in three frequency ranges

\begin{tabular}{|c|c|c|c|c|c|c|}
\hline \multirow{2}{*}{ Working frequency } & \multicolumn{6}{|c|}{ Antenna parameters } \\
\hline & $\Delta T_{b r},\left({ }^{\circ} \mathrm{C}\right)$ & $W_{z}(\mathbf{m m})$ & $W_{x}(\mathrm{~mm})$ & $W_{y}(\mathrm{~mm})$ & $V_{x}(\mathrm{~mm}), 10 \mathrm{~mm}$ & $V_{y}(\mathrm{~mm}), 10 \mathrm{~mm}$ \\
\hline $2.3 \mathrm{GHz}$ & 0.7 & 40 & 51 & 52 & 24 & 18.6 \\
\hline $3.3 \mathrm{GHz}$ & 0.7 & 26 & 43.5 & 28 & 27.3 & 33.3 \\
\hline $4.3 \mathrm{GHz}$ & 0.7 & 18 & 39.9 & 24 & 27.9 & 40.9 \\
\hline
\end{tabular}

\section{Results of the study of the ring printed ultra-wideband miniature antenna}

As a result of theoretical studies, an original version of the design of a printed ultra-wideband miniature antenna was developed, which can be used as part of a multi-channel multi-frequency microwave radiometer. An antenna design with a ring-shaped radiator has been developed, which provides reception of microwave radiation from biological tissues in the range of $1800-4600 \mathrm{MHz}$. The results of numerical simulation of the antenna electromagnetic field in the tissues of a biological object by the numerical method of finite differences in the time domain (FDTD) are presented. The developed antenna has a height of $6 \mathrm{~mm}$ and weighs $5 \mathrm{~g}$. As a dielectric substrate, let's propose to use ceramic-polymer composites, namely, polydimethylsiloxane (PDMS) polymer Sylgard-184, Dow Silicones Corporation, USA) [35] and barium titanate [36]. The relative dielectric constant of PDMS is low. To increase the relative dielectric constant, the required amount of barium titanate is added, which makes it possible to achieve the required dielectric constant values. The calculation of the antenna parameters (measurement depth, resolution and distribution of radiation power over the volume of biological tissue, sensitivity, etc.) in three frequency ranges has been carried out.

\section{Discussion of the results of the study of the ultra-wideband printed antenna}

As a result of theoretical studies, data have been obtained that make it possible to create a real prototype of an antenna for a multi-channel multi-frequency radiometer. A distinctive feature of the antenna under consideration is a very wide bandwidth $(2800 \mathrm{MHz})$, which is 4 times more than antennas used in serial devices. This opens up the possibility of using this antenna for constructing multi-frequency radiometers. It is curious that the proposed antenna has an even wider bandwidth in terms of the reflection coefficient. The results shown in Fig. 3 show that up to a frequency of $7000 \mathrm{GHz}$ the antenna VSWR is less than 2. However, at frequencies above $4600 \mathrm{MHz}$, the field in the biological object is noticeably distorted and acquires a multi-beam character. This is not critical the case in many applications, but it is necessary to have a single main beam antenna pattern to detect temperature anomalies. Therefore, the working band of the proposed antenna is limited to 4,600 MHz.

Analysis of the measurement area in different frequency ranges shows that as the operating frequency increases, the temperature measurement area decreases noticeably. This is clearly shown in Fig. 6. In this case, the depth of measurement also decreases, which opens up the possibility of reconstructing the thermodynamic temperature based on the brightness temperatures measured at different frequencies. In addition to a decrease in the measurement depth, with an increase in the 
operating frequency, a noticeable decrease in the width of the measurement region along the $Y(W y)$ axis occurs. The measurement area decreases along the $X$ axis, but not so noticeably. In general, the antenna measurement area is comparable to other antennas used in radiometry [14]. Obviously, with an increase in the operating frequency, the losses in the breast tissue increase, which leads to a decrease in the measurement depth. It could be assumed that this would lead to a decrease in the measured brightness on the projection of a malignant tumor and decrease the sensitivity of the microwave radiometry. However, calculations have shown that this does not happen, and the increase in the brightness temperature at all frequencies for a malignant tumor with a diameter of $10 \mathrm{~mm}$, located at a depth of $10 \mathrm{~mm}$, is $\approx 0.7^{\circ} \mathrm{C}$. This can be explained by the fact that with increasing frequency the volume of temperature averaging ( $W x$ and $W y$ ) decreases and, as a result, the brightness temperature on the tumor projection does not change with increasing frequency. At the same time, without a tumor, the brightness temperature will decrease as the frequency increases, due to a decrease in the measurement depth. Thus, the sensitivity of the method will not decrease at high frequencies. But at high frequencies it will be much easier to provide the necessary noise immunity of the device and the measurement results are more stable.

The proposed measurement depth is somewhat less than that of waveguide antennas due to the design features of printed antennas. This is due to the predominance of the $Z$-component of the electric field, which expands the measurement area along the $X$ and $Y$ axes. According to [14], the parameters of the measurement area for waveguide antennas $\varnothing 22 \mathrm{~mm}$ in the $3.8 \mathrm{GHz}$ range ( $W z=46 \mathrm{~mm}, W x=48 \mathrm{~mm}, W y=68 \mathrm{~mm}$ ) is higher than that of the developed antenna (Table 1). However, the temperature rise on the tumor projection $(\varnothing 10 \mathrm{~mm}$, depth $-10 \mathrm{~mm})$ for the proposed antenna is $0.7^{\circ} \mathrm{C}$, which is $0.2^{\circ} \mathrm{C}$ less than that of the waveguide antenna. Therefore, when used as part of a multi-channel system, such differences will not be significant. At the same time, it is not possible to use a waveguide antenna as part of a multi-channel multi-frequency microwave radiometer due to the narrow operating frequency band of $700 \mathrm{MHz}$ instead of $2600 \mathrm{MHz}$ and a cumbersome design (the height of the waveguide antenna is $45 \mathrm{~mm}$ and a mass of about $100 \mathrm{~g}$ instead of a height of $6 \mathrm{~mm}$ and a mass of $5 \mathrm{~g}$ for the proposed printed) antenna.

Considering the presence of an ultra-wide bandwidth of operating frequencies and small dimensions, the proposed antenna can be used as a sensor of a multi-frequency multichannel radiothermograph, which provides $3 \mathrm{D}$ visualization of the distribution of internal thermodynamic temperatures of biological tissues. At the next stages of development, it is planned to manufacture a prototype of the antenna, experimental verification of its characteristics, as well as medical testing as part of a multi-channel conformal antenna system.

\section{Conclusions}

The paper presents the characteristics of a small-sized broadband printed ring antenna designed to measure microwave radiation of biological tissues in the frequency range $1.8-4.6 \mathrm{GHz}$. This antenna can be used as part of a multi-channel multi-frequency radiometer. The studies are carried out using numerical modeling using the FDTD method. Antenna parameters are optimized to obtain optimal parameters of matching and optimal rational antenna parameters. The frequency characteristics of the VSWR are calculated. Calculations have shown that the antenna has a reflection level in the working band of no more than $-10 \mathrm{~dB}$. Based on the results of mathematical modeling (VSWR $<2$, the measurement depth was $18-40 \mathrm{~mm}$, the bandwidth was more than $2500 \mathrm{MHz}$ ), the optimal antenna design was selected. The necessary data for the manufacture of the antenna prototype and subsequent tests have been obtained. As a result of numerical simulation, the optimal geometric parameters of the antenna were obtained: $D 1=22 \mathrm{~mm}, D 2=20 \mathrm{~mm}, h=1.28 \mathrm{~mm}$, $S=2 \mathrm{~mm}, \operatorname{Din} \_1=17 \mathrm{~mm}, \operatorname{Din} 2=8.5 \mathrm{~mm}, H=10 \mathrm{~mm}$ and dielectric substrate permeability $\varepsilon=27$. As a dielectric substrate, let's propose to use ceramic-polymer composites, namely, polydimethylsiloxane (PDMS) polymer Sylgard-184, Dow Silicones Corporation, USA) with barium titanate, which provide the required dielectric constant of the substrate. The antenna proposed for implementation in the form of a printed radiator of an ring shape is distinguished by its simplicity of design, compactness, small dimensions and a wide operating frequency band. The antenna can be used as part of a multi-channel multi-frequency microwave medical radiothermograph. 


\section{Acknowledgement}

Research was supported by a grant of the Russian Science Foundation (project No. 19-19-00349).

\section{References}

[1] Microwave radiometry in medicine. Available at: http://www.radiometry.ru/rtm-01-res/description/

[2] Vesnin, S., Turnbull, A. K., Dixon, J. M., Goryanin, I. (2017). Modern Microwave Thermometry for Breast Cancer. Journal of Molecular Imaging \& Dynamics, 7 (2). doi: https://doi.org/10.4172/2155-9937.1000136

[3] Goryanin, I., Karbainov, S., Shevelev, O., Tarakanov, A., Redpath, K., Vesnin, S., Ivanov, Y. (2020). Passive microwave radiometry in biomedical studies. Drug Discovery Today, 25 (4), 757-763. doi: https://doi.org/10.1016/j.drudis.2020.01.016

[4] Toutouzas, K., Grassos, H., Synetos, A., Drakopoulou, M., Tsiamis, E., Moldovan, C. et. al. (2011). A new non-invasive method for detection of local inflammation in atherosclerotic plaques: Experimental application of microwave radiometry. Atherosclerosis, 215 (1), 82-89. doi: https://doi.org/10.1016/j.atherosclerosis.2010.12.019

[5] Toutouzas, K., Synetos, A., Nikolaou, C., Stathogiannis, K., Tsiamis, E., Stefanadis, C. (2012). Microwave radiometry: a new non-invasive method for the detection of vulnerable plaque. Cardiovascular diagnosis and therapy, 2 (4), 290-297. doi: http:// doi.org/10.3978/j.issn.2223-3652.2012.10.09

[6] Rodrigues, D. B., Stauffer, P. R., Pereira, P. J. S., Maccarini, P. F. (2018). Microwave Radiometry for Noninvasive Monitoring of Brain Temperature. Emerging Electromagnetic Technologies for Brain Diseases Diagnostics, Monitoring and Therapy, 87-127. doi: https://doi.org/10.1007/978-3-319-75007-1_5

[7] Kublanov, V. S. (2013). Microwave Radiation as Interface to the Brain Functional State. Proceedings of the International Conference on Biomedical Electronics and Devices, 318-322. doi: https://doi.org/10.5220/0004371703180322

[8] Cheboksarov, D. V., Butrov, A. V., Shevelev, O. A. et al. (2015). Diagnostic opportunities of noninvasive brain thermomonitoring. Anesteziologiia i Reanimatologiia, 60 (1) 66-69. Available at: https://europepmc.org/article/med/26027230

[9] Crandall, J. P., O, J. H., Gajwani, P., Leal, J. P., Mawhinney, D. D., Sterzer, F., Wahl, R. L. (2018). Measurement of Brown Adipose Tissue Activity Using Microwave Radiometry and18F-FDG PET/CT. Journal of Nuclear Medicine, 59 (8), $1243-1248$. doi: https://doi.org/10.2967/jnumed.117.204339

[10] Zinovyev, S. V. (2018). New Medical Technology - Functional Microwave Thermography: Experimental Study. KnE Energy, 3 (2), 547. doi: https://doi.org/10.18502/ken.v3i2.1864

[11] Arunachalam, K., Maccarini, P., De Luca, V., Tognolatti, P., Bardati, F., Snow, B., Stauffer, P. (2011). Detection of Vesicoureteral Reflux Using Microwave Radiometry - System Characterization With Tissue Phantoms. IEEE Transactions on Biomedical Engineering, 58 (6), 1629-1636. doi: https://doi.org/10.1109/tbme.2011.2107515

[12] Gudkov, A. G., Leushin, V. Y., Sidorov, I. A., Vesnin, S. G., Porokhov, I. O., Sedankin, M. K. et. al. (2019). Use of Multichannel Microwave Radiometry for Functional Diagnostics of the Brain. Biomedical Engineering, 53 (2), 108-111. doi: https:// doi.org/10.1007/s10527-019-09887-Z

[13] Gudkov, A. G., Leushin, V. Y., Vesnin, S. G., Sidorov, I. A., Sedankin, M. K., Solov'ev, Y. V. et. al. (2020). Studies of a Microwave Radiometer Based on Integrated Circuits. Biomedical Engineering, 53 (6), 413-416. doi: https://doi.org/10.1007/s10527-020-09954-w

[14] Sedankin, M., Skuratov, V., Nelin, I., Mershin, L., Leushin, V., Vesnin, S. (2020). System of rational parameters of antennas for designing a multi-channel multi-frequency medical radiometer. 2020 International Conference on Actual Problems of Electron Devices Engineering (APEDE). IEEE, 154-159. Available at: https://www.researchgate.net/publication/344548359_System_ of_Rational_Parameters_of_Antennas_for_Designing_a_Multi-channel_Multi-frequency_Medical_Radiometer

[15] Vesnin, S. G. (2008). Pat. No. 2407429 RF. Antenna-applicator and device for determining temperature changes of internal tissues of biological object and methods of determining temperature changes and cancer risk detection. No. 2008151958/14; declareted: 26.12.2008; published: 27.12.2010, Bul. No. 36. Available at: https://elibrary.ru/item.asp?id=37737636

[16] Sedankin, M. K., Vesnin, S. G., Leushin, V. Yu., Agasieva, S. V., Chizhikov, S. V., Nazarov, V. V. et. al. (2020). Diagnostic conformal system for brain neuroimaging by using a multichannel radio thermometer based on monolithic integrated circuits. Nanotehnologii: razrabotka, primenenie - XXI vek, 12 (1), 43-50. Available at: https://elibrary.ru/item.asp?id=42757793

[17] Popovic, Z., Momenroodaki, P., Scheeler, R. (2014). Toward wearable wireless thermometers for internal body temperature measurements. IEEE Communications Magazine, 52 (10), 118-125. doi: https://doi.org/10.1109/mcom.2014.6917412

[18] Rodrigues, D. B., Maccarini, P. F., Salahi, S., Oliveira, T. R., Pereira, P. J. S., Limao-Vieira, P. et. al. (2014). Design and Optimization of an Ultra Wideband and Compact Microwave Antenna for Radiometric Monitoring of Brain Temperature. IEEE Transactions on Biomedical Engineering, 61 (7), 2154-2160. doi: https://doi.org/10.1109/tbme.2014.2317484

[19] Lee, J. W., Lee, S. M., Kim, K. S., Han, W. T., Yoon, G., Pasmanik, L. A. et. al. (2004). Experimental investigation of the mammary gland tumour phantom for multifrequency microwave radio-thermometers. Medical \& Biological Engineering \& Computing, 42 (5), 581-590. doi: https://doi.org/10.1007/bf02347538 
[20] Chupina, D. N., Sedankin, M. K., Vesnin, S. G. (2017). Application of modern technologies of mathematical simulation for the development of medical equipment. 2017 IEEE 11th International Conference on Application of Information and Communication Technologies (AICT). doi: https://doi.org/10.1109/icaict.2017.8687066

[21] Klemetsen, O., Jacobsen, S. (2012). Improved Radiometric Performance Attained by an Elliptical Microwave Antenna With Suction. IEEE Transactions on Biomedical Engineering, 59 (1), 263-271. doi: https://doi.org/10.1109/tbme.2011.2172441

[22] Groumpas, E., Koutsoupidou, M., Uzunoglu, N., Karanasiou, I. S. (2017). Sensing local temperature and conductivity changes in a brain phantom using near-field microwave radiometry. 2017 International Workshop on Antenna Technology: Small Antennas, Innovative Structures, and Applications (iWAT). doi: https://doi.org/10.1109/iwat.2017.7915383

[23] Iudicello, S. (2009). Microwave radiometry for breast cancer detection. Universita' degli studi tor vergata Roma, dipartimento di informatica, sistemi e produzione geoinformation research doctorate. Rome, 111.

[24] Beaucamp-Ricard, C., Dubois, L., Vaucher, S., Cresson, P.-Y., Lasri, T., Pribetich, J. (2009). Temperature Measurement by Microwave Radiometry: Application to Microwave Sintering. IEEE Transactions on Instrumentation and Measurement, 58 (5), 1712-1719. doi: https://doi.org/10.1109/tim.2008.2009189

[25] Vesnin, S. G., Sedankin, M. K., Gudkov, A. G., Leushin, V. Y., Sidorov, I. A., Porokhov, I. O. et. al. (2020). A Printed Antenna with an Infrared Temperature Sensor for a Medical Multichannel Microwave Radiometer. Biomedical Engineering. doi: https://doi.org/10.1007/s10527-020-10011-9

[26] Tofighi, M.-R. (2011). Characterization of biomedical antennas for microwave heating, radiometry, and implant communication applications. WAMICON 2011 Conference Proceedings. doi: https://doi.org/10.1109/wamicon.2011.5872874

[27] León, G., Herrán, L. F., Mateos, I., Villa, E., Ruiz-Alzola, J. B. (2020). Wideband Epidermal Antenna for Medical Radiometry. Sensors, 20 (7), 1987. doi: https://doi.org/10.3390/s20071987

[28] Shabashov, E. P., Shabunin, S. N., Mrdakovic, B. (2020). Modeling and analysis of the spiral antenna properties for the research of the brain radiatio in the microwave range. Ural Radio Engineering Journal, 4 (1), 84-99. doi: https://doi.org/ 10.15826/urej.2020.4.1.005

[29] Abufanas, H., Hadi, R. J., Sandhagen, C., Bangert, A. (2015). New approach for design and verification of a wideband Archimedean spiral antenna for radiometric measurement in biomedical applications. 2015 German Microwave Conference. doi: https://doi.org/10.1109/gemic.2015.7107769

[30] Zakirov, A., Belousov, S., Valuev, I., Levchenko, V., Perepelkina, A., Zempo, Y. (2017). Using memory-efficient algorithm for large-scale time-domain modeling of surface plasmon polaritons propagation in organic light emitting diodes. Journal of Physics: Conference Series, 905, 012030. doi: https://doi.org/10.1088/1742-6596/905/1/012030

[31] Valuev, I., Deinega, A., Knizhnik, A., Potapkin, B. (2007). Creating Numerically Efficient FDTD Simulations Using Generic C++ Programming. Computational Science and Its Applications - ICCSA 2007, 213-226. doi: https://oi.org/10.1007/ 978-3-540-74484-9_19

[32] IFAC. Available at: http://niremf.ifac.cnr.it/tissprop/htmlclie/htmlclie.php

[33] Gabriel, S., Lau, R. W., Gabriel, C. (1996). The dielectric properties of biological tissues: II. Measurements in the frequency range $10 \mathrm{~Hz}$ to $20 \mathrm{GHz}$. Physics in Medicine and Biology, 41 (11), 2251-2269. doi: https://doi.org/10.1088/0031-9155/41/11/002

[34] Li, X., Hagness, S. C. (2001). A confocal microwave imaging algorithm for breast cancer detection. IEEE Microwave and Wireless Components Letters, 11 (3), 130-132. doi: https://doi.org/10.1109/7260.915627

[35] Salvado, R., Loss, C., Gonçalves, R., Pinho, P. (2012). Textile Materials for the Design of Wearable Antennas: A Survey. Sensors, 12 (11), 15841-15857. doi: https://doi.org/10.3390/s121115841

[36] Koulouridis, S., Kiziltas, G., Zhou, Y., Hansford, D. J., Volakis, J. L. (2006). Polymer-Ceramic Composites for Microwave Applications: Fabrication and Performance Assessment. IEEE Transactions on Microwave Theory and Techniques, 54 (12), 4202-4208. doi: https://doi.org/10.1109/tmtt.2006.885887 